\title{
Mid-latitude Summer Nighttime Anomaly (MSNA) - observations and model simulations
}

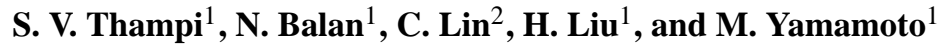 \\ ${ }^{1}$ Research Institute for Sustainable Humanosphere (RISH), Kyoto University, 611-0011, Japan \\ ${ }^{2}$ Department of Earth Science, National Cheng Kung University, Tainan, Taiwan
}

Received: 4 September 2010 - Revised: 13 November 2010 - Accepted: 20 December 2010 - Published: 14 January 2011

\begin{abstract}
In this paper, we present model simulations of the Mid-latitude Summer Nighttime Anomaly (MSNA) in the Northern Hemisphere, which is characterized by noontime dip and evening maximum in the diurnal variation of the ionospheric density. The simulations are carried out using SUPIM (Sheffield University Plasmasphere Ionosphere Model) for solar minimum at $135^{\circ} \mathrm{E}$ longitude where MSNA is most pronounced in the Northern Hemisphere. The simulations are used to understand the relative importance of electric fields, and zonal and meridional winds in the formation of MSNA. The wind velocities measured by the Middle and Upper atmosphere radar (MU radar) and those obtained from the horizontal wind model (HWM93) are used. The results show that the formation of MSNA is closely related to the diurnal variation of the neutral winds with little contribution from the changes in the electric fields. The observed features of MSNA are better reproduced when MU radar winds are used as model input rather than HWM winds.
\end{abstract}

Keywords. Ionosphere (Mid-latitude ionosphere; Modeling and forecasting)

\section{Introduction}

It has long been realized that the diurnal variation of the midlatitude night time density often departs from a simple solar controlled behavior. A classic example of this is the Weddell Sea Anomaly (WSA), which occurs during the southern hemispheric summer period (e.g., Bellchambers and Piggott, 1958; Horvath and Essex, 2000, 2003; Horvath, 2006; Jee et al., 2009; Lin et al., 2009). The WSA is characterized by a reversal of the normal diurnal cycle, with electron density maximizing between 22:00 LT and local midnight, and the

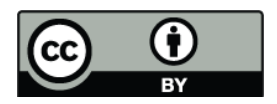

Correspondence to: S. V. Thampi (smithathampi.rish@gmail.com) diurnal minimum occurring near local noon. Recently, similar feature has been observed in the northern mid-latitudes during local summer (Lin et al., 2009, 2010; Thampi et al., 2009; Horvath and Lovell, 2009; Liu et al., 2010). The term Mid-latitude Summer Nighttime Anomaly (MSNA) is now being used to describe the anomalous electron density patterns in both Northern and Southern Hemispheres (Thampi et al., 2009; Lin et al., 2010). It must be mentioned here that the MSNA is different from winter nighttime enhancements (Evans, 1965; Titheridge, 1968; Davies et al., 1979; Balan and Rao, 1987; Luan et al., 2008), and northern hemispheric summer nighttime enhancements reported by Balan and Bailey (1992) and Balan et al. (1994) since the latter ones appear as a secondary maximum in electron density, both in the premidnight and post-midnight hours.

Based on the local time variations of ionospheric peak height and calculations of the effective neutral wind velocity, it has been suggested that the neutral wind in the geomagnetic frame could be the main driver of MSNA (He et al., 2009; Liu et al., 2010). However, it was also suggested that the field-aligned plasma flow from the protonosphere can cause mid-latitude nighttime density enhancements (Bailey et al., 1991; Liu et al., 2010). The cross-L compression of the ionosphere, caused by the ionospheric westward electric field (reverse fountain at low-latitudes) is also identified as a factor that can accelerate the downward plasma flow, causing enhancements in the mid-latitudes (Davies et al., 1979; Horvath and Lovell, 2009). In contrast, Lin et al. (2010) have suggested that an enhanced eastward electric field at the equator (enhanced fountain) around 18:00 LT-20:00 LT is a necessary condition along with the presence of equatorward winds, for the formation of MSNA both in the Northern and Southern Hemispheres. In this context, the present paper reports observations of the Northern Hemispheric MSNA along with model simulations using Sheffield University Plasmasphere Ionosphere Model (SUPIM). The MSNA in the Northern Hemisphere is most pronounced from $\sim 110^{\circ} \mathrm{E}$ up to the

Published by Copernicus Publications on behalf of the European Geosciences Union. 


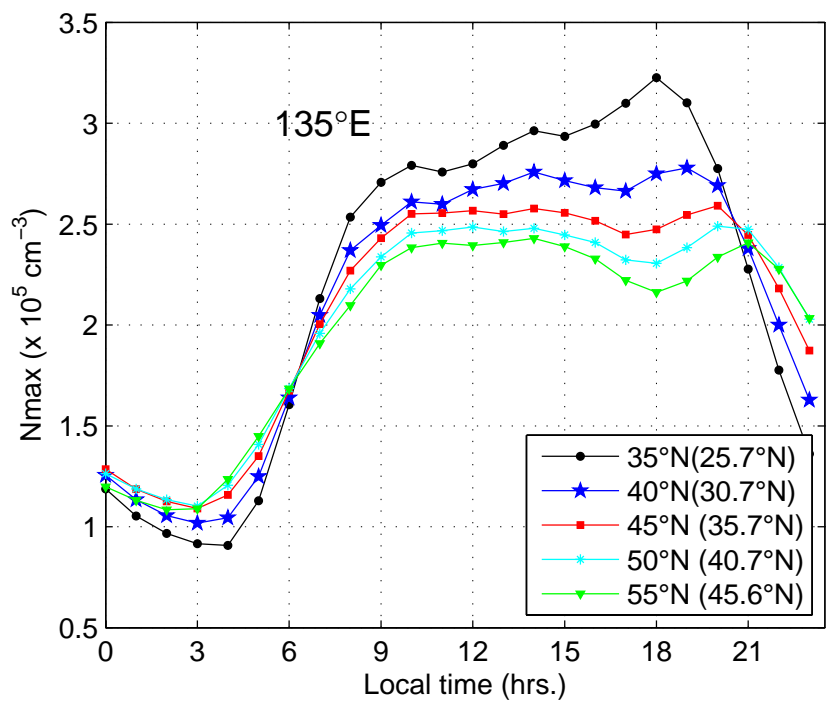

Fig. 1. Local time variation of $N_{\max }$ at various latitudes during July 2008 , obtained from $\mathrm{F} 3 / \mathrm{C}$ measurements corresponding to $135^{\circ} \mathrm{E}$ longitude.

Pacific Northeast (around Japan and Sea of Okhotsk) region, i.e., $\sim 170^{\circ} \mathrm{E}$ (Lin et al., 2009; Liu et al., 2010; Horvath and Lovell, 2009). Hence, we choose the Japanese longitude $\left(135^{\circ} \mathrm{E}\right)$ for the simulations of the MSNA, where we had tomographic observations as well (Thampi et al., 2009). The uniqueness of these simulations is that we incorporated the neutral wind velocities for solar minimum conditions observed by the Middle and Upper atmosphere radar (MU radar, $\left.34.85^{\circ} \mathrm{N}, 136.1^{\circ} \mathrm{E}\right)$ located near the peak longitude of MSNA (Kawamura et al., 2000). Section 2 summarizes the observed characteristics of MSNA, and the SUPIM simulations are presented in Sect. 3. Section 4 contains a brief discussion of the generation mechanism of MSNA.

\section{Observations}

First, we present few observations of MSNA using the radio occultation (RO) measurements by the FORMOSAT3/COSMIC (F3/C) satellites. The data are obtained from the standard inversion routine by the COSMIC Data Analysis and Archival Center (CDAAC). In the CDAAC ionospheric inversion, an assumption of straight-line propagation of the GPS signal through the ionosphere by neglecting the bending angle is made. The total electron content (TEC) along the ray paths between GPS satellite and F3/C are converted to a vertical electron density profile using the Abel transform with an analytical solution to avoid the singularities at the top and lower limits (for details see, Hajj et al., 2000; Syndergaard et al., 2006; Anthes et al., 2008, and references therein). Figure 1 shows the local time variation of maximum electron density $\left(N_{\max }\right)$ at $135^{\circ} \mathrm{E}$ longitude sector during July 2008 , corresponding to $35^{\circ} \mathrm{N}$ to $55^{\circ} \mathrm{N}$ ge-

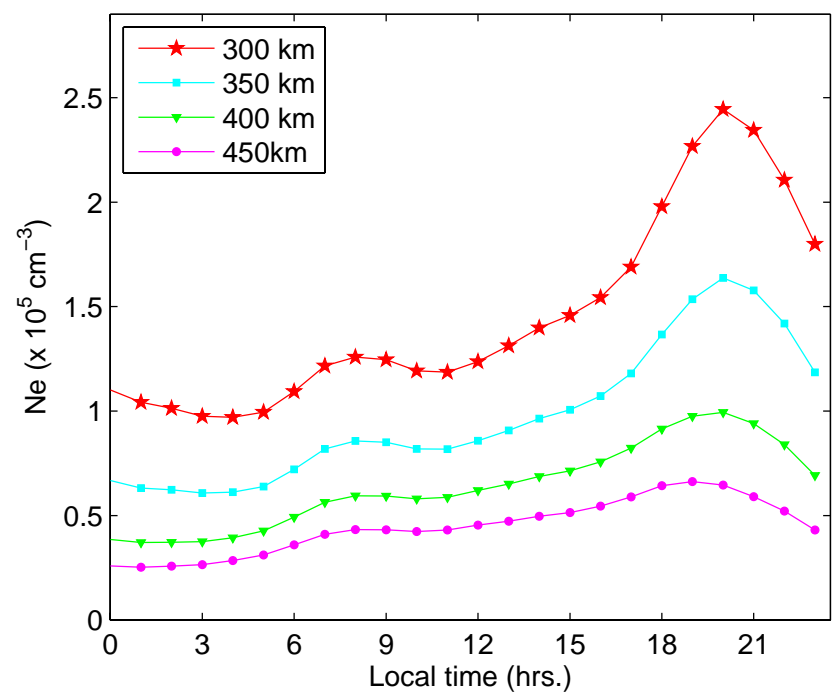

Fig. 2. Local time variation of electron densotity at various altitudes, at $\left(45^{\circ} \mathrm{N}, 135^{\circ} \mathrm{E}\right)$ during July 2008 , obtained from F3/C measurements.

ographic latitudes. It can be seen that at $35^{\circ} \mathrm{N}$, the diurnal maximum of electron density appears to be around 18:00 LT. At $40^{\circ} \mathrm{N}$, this happens at around 19:30 LT, whereas at $45^{\circ} \mathrm{N}$, the diurnal maximum appears close to 20:30 LT. At $50^{\circ} \mathrm{N}$ and $55^{\circ} \mathrm{N}$, this occurs at 21:00 LT. The MSNA is most clearly seen at latitudes $45-50^{\circ} \mathrm{N}$. Another important feature which is to be noticed in this figure is that from 06:00 LT-20:00 LT, the electron density at $35^{\circ} \mathrm{N}$ is the highest, and it decreases with latitude to reach a minimum at $55^{\circ} \mathrm{N}$. This trend reverses at around 20:00 LT, and from 20:00 LT to midnight, the electron density is less at $35^{\circ} \mathrm{N}$ and gradually increases with latitude. This trend persists in the post-midnight hours also with lesser latitudinal gradients. This feature is a consequence of the phase reversal of the diurnal cycle (MSNA), because the nighttime enhancement causes the density to remain higher in the mid-latitudes than that at the low-latitude region, resulting in the reversal of the latitudinal gradients. Figure 2 shows the local time variation of electron density at different altitudes, corresponding to $45^{\circ} \mathrm{N}$ latitude $\left(35.7^{\circ} \mathrm{N}\right.$ magnetic), in the same longitude sector. The nighttime maximum in the electron density is clearly seen at 300, 350, 400 and $450 \mathrm{~km}$, with its amplitude decreasing with increasing altitude. The "noon-time dip" in the electron density is also very clearly seen especially at 300 and $350 \mathrm{~km}$ altitudes.

In Fig. 2 we show the electron density from radio occultation (RO) measurements at altitudes from $300 \mathrm{~km}$ upwards only because of the errors in the RO measurements of electron density at lower altitudes (J. Y. Liu et al., 2010). However, we use the tomographically estimated electron density profiles to see the altitude structure of MSNA. Figure 3 shows the altitude profiles at $40^{\circ} \mathrm{N}$ latitude, corresponding to 14:00 LT and 20:00 LT obtained on different days along 

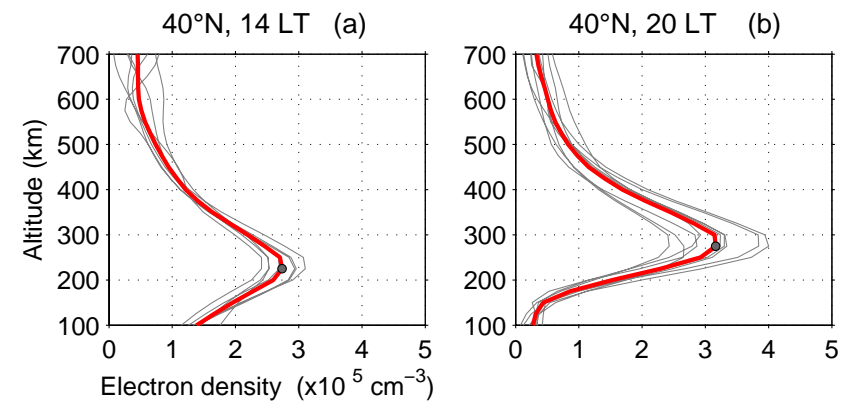

Fig. 3. Altitude profiles of electron density at $40^{\circ} \mathrm{N}$, corresponding to 14:00 LT and 20:00 LT from tomography. The red curves indicate mean. The dot shows the maximum electron density.

with their mean profiles. These profiles are extracted from the tomographic images obtained from 10 July to $31 \mathrm{Au}-$ gust, at local time (LT) centered on the 2-h period, and hence represents the variability within those $2 \mathrm{~h}$. The total electron content (TEC) data for the tomographic reconstruction are obtained from the GRBR (GNU Radio Beacon Receiver, GNU is the acronym for GNU is Not Unix) network operational in Japan (Thampi et al., 2009; Thampi and Yamamoto, 2010). Two aspects of MSNA are clearly seen in this figure: (1) MSNA is absent at lower altitudes (for instance at $200 \mathrm{~km}$ and $225 \mathrm{~km}$ ); the density at these low altitudes are greater at 14:00 LT than at 20:00 LT, and (2) MSNA is a feature that exists at altitudes near and above the ionospheric peak (very prominently at altitudes of $\sim 275-450 \mathrm{~km}$ ), and less so at higher altitudes. This corroborates with the earlier observations of Weddell Sea anomaly (WSA) and MSNA (Lin et al., 2009, 2010). It is also clear that the $h m \mathrm{~F} 2$ changes from $225 \mathrm{~km}$ at 14:00 LT to $275 \mathrm{~km}$ at 20:00 LT. Such a height change can be due to the equatorward winds operating at night. In fact, the wind can affect the movement of the ionosphere as a whole as explained by Liu et al. (2010). If considering a fixed altitude (e.g., $300 \mathrm{~km}$ ), one can see that this region is away from $h m \mathrm{~F} 2$ during daytime, while at night, the entire ionosphere moves upwards which makes $300 \mathrm{~km}$ more close to $h m \mathrm{~F} 2$ due to the equatorward winds. Consequently, the plasma density at $300 \mathrm{~km}$ will increase at night compared to daytime. This aspect could be uniquely observed because we obtain the altitude profiles using tomography. The other factor is that at night, the lifting of ionosphere to higher heights where the recombination rates are less enables the plasma to live longer. These aspects of MSNA indicate the importance of equatorward neutral winds in the formation of MSNA; the mechanism is similar to the equatorward wind producing positive ionospheric storms (Balan et al., 2009).

Figure 4 shows the average latitudinal distribution of electron densities at $300 \mathrm{~km}$ from 16:00 LT to 22:00 LT obtained from tomography. Along with this, the latitudinal distribution of electron density at $300 \mathrm{~km}$ obtained from F3/C occultation measurements (18:00 LT and 22:00 LT), at $240^{\circ} \mathrm{E}$

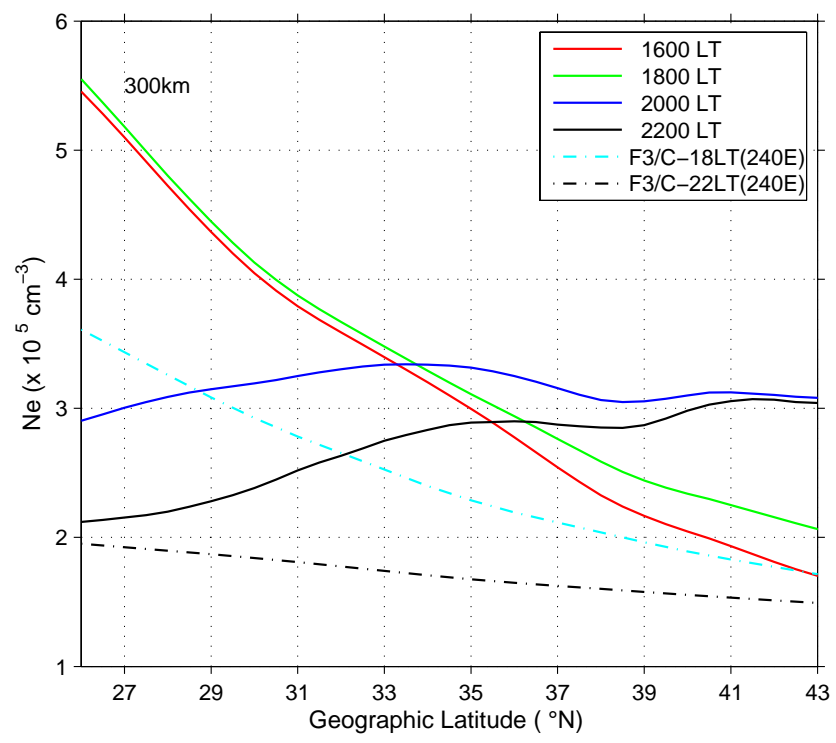

Fig. 4. Latitudinal variation of electron density at $300 \mathrm{~km}$, for different LTs, obtained from tomography. The F3/C observations of the latitudinal variation of electron density at $300 \mathrm{~km}$, along the $240^{\circ} \mathrm{E}$ sector are also shown.

longitude in July 2008 is also plotted. As discussed earlier, the tomographic observations show a southward gradient at 16:00 LT, corresponding to the EIA. This disappears later, and at 20:00 LT, we can see that the densities in the latitudes $<33^{\circ} \mathrm{N}$ shows a sharp decrease from the previous values. Unlike this, in the region $>33^{\circ} \mathrm{N}$, the electron density at $300 \mathrm{~km}$ shows a considerable increase. These changes are significant and beyond any possible error in the tomographic reconstruction. At 22:00 LT, the densities up to $\sim 40^{\circ}$ show a decrease, whereas the densities at latitudes $>41^{\circ} \mathrm{N}$ remain more or less the same. The small change seen above $>37^{\circ}$ (from 20:00 LT-22:00 LT) could be within the errors due to the inversion procedure and hence considered insignificant, whereas for the latitudes from $26-37^{\circ} \mathrm{N}$, the changes are significant. It has been shown earlier that the density maximum actually occurs around 20:00-21:00 LT at these latitudes (Thampi et al., 2009; Liu et al., 2010). To examine whether there is any longitudinal variation for the MSNA during this period, we have also used the $\mathrm{F} 3 / \mathrm{C}$ data corresponding to $240^{\circ} \mathrm{E}$ longitude. This longitude was chosen because previous observations showed that this region does not show the MSNA feature (Liu et al., 2010). The latitudinal distribution of electron density at $300 \mathrm{~km}$ at 18:00 LT and 22:00 LT obtained from $\mathrm{F} 3 / \mathrm{C}$ radio occultation measurements at $240^{\circ} \mathrm{E}$ longitude are also shown. It can be seen that the MSNA feature is clearly absent in this longitude sector. These figures summarize the important observed characteristics of MSNA, which agree with the previous observations (e.g. Lin et al., 2009; Liu et al., 2010). 

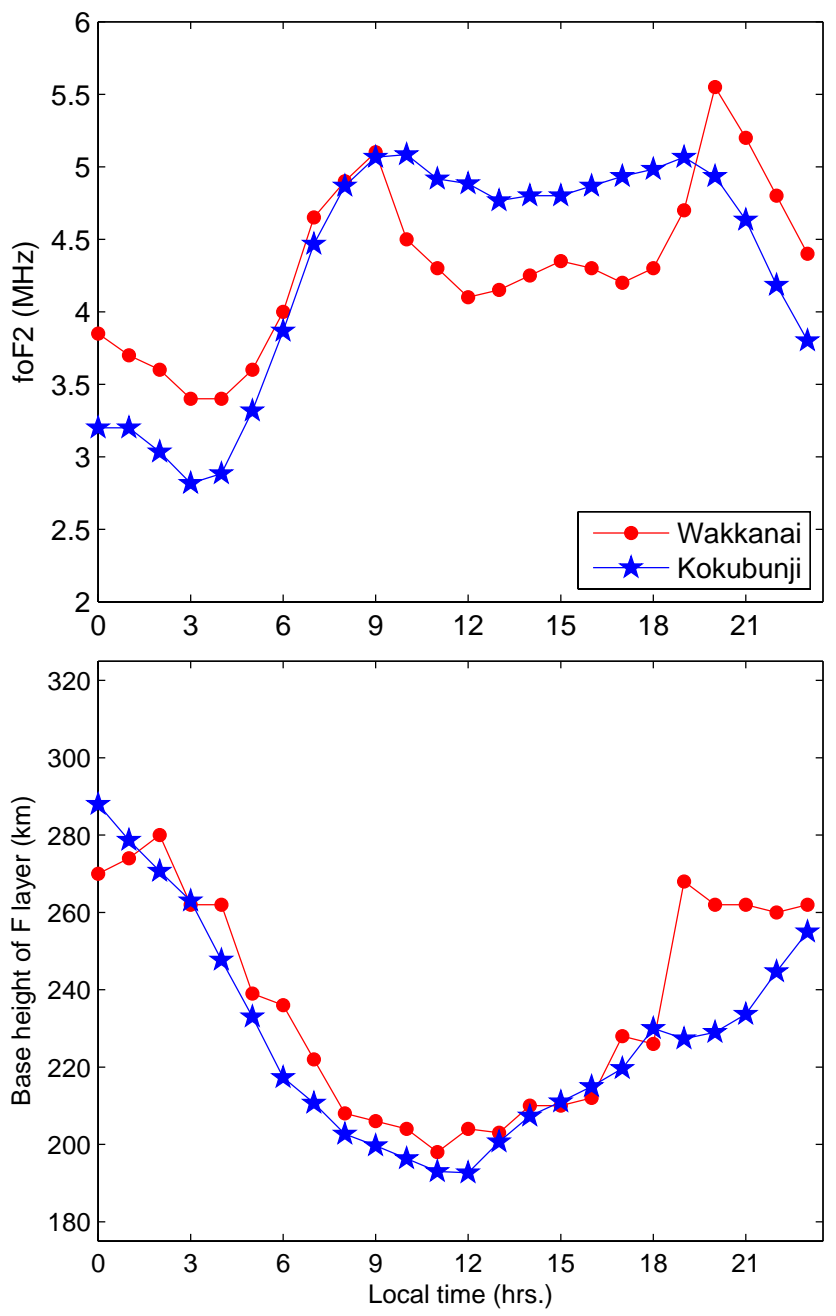

Fig. 5. Temporal variation of monthly mean foF2 (top) and $h^{\prime} F$ (bottom) from Wakkanai and Kokubunji during July 2008.

Figure 5 shows local time variation of the monthly mean values of $f o \mathrm{~F} 2$ (top panel) and $h m \mathrm{~F} 2$ (bottom panel), from ionosonde observations at Wakkanai $\left(45.4^{\circ} \mathrm{N}, 141.7^{\circ} \mathrm{E}\right)$, where MSNA is clearly seen and Kokubunji $\left(35.7^{\circ} \mathrm{N}\right.$, $139.5^{\circ} \mathrm{E}$, geographic), where MSNA is mostly absent. The nighttime peak and the noon-time dip in electron density are seen at Wakkanai, but not at Kokubunji, corroborating the F3/C observations. An interesting feature that can be noticed is that, at Wakkanai, the $h m \mathrm{~F} 2$ shows an increase before the sunset, and continues to stay at a higher altitude compared to that at Kokubunji. The diurnal maximum in electron density occurs after this height enhancement take place. The ionosonde observations are also indicative of the importance of wind-induced lifting of the ionosphere for the generation of MSNA.

\section{SUPIM simulations}

The physics-based model SUPIM (Bailey et al., 1997) is used for the calculations. The model solves the coupled timedependent equations of continuity, momentum, and energy for the electrons and ions $\left(\mathrm{O}^{+}, \mathrm{H}^{+}, \mathrm{He}^{+}, \mathrm{N}_{2}^{+}, \mathrm{NO}^{+}\right.$, and $\mathrm{O}_{2}^{+}$) along closed eccentric-dipole geomagnetic field lines. For this study, 165 field lines with apex altitude distributed from $150 \mathrm{~km}$ to $12000 \mathrm{~km}$ are used, with apex intervals of $10 \mathrm{~km}$ up to $400 \mathrm{~km}$ and $25 \mathrm{~km}$ from 400 to $1000 \mathrm{~km}$. The calculations are for the Japanese longitude $\left(135^{\circ} \mathrm{E}\right)$ for 20 July 2008 , which is a magnetically quiet day $(\mathrm{AP}=3)$ under low solar activity $(\mathrm{F} 10.7=65.9)$, local summer season. On this day, MSNA was observed using tomography, in an image obtained at 20:00 LT, above $\sim 35^{\circ} \mathrm{N}$ geographic latitude (not illustrated).

The electrodynamics is taken care of by using the vertical $\boldsymbol{E} \times \boldsymbol{B}$ drift velocities measured by the incoherent scatter radar at Jicamarca (Fejer et al., 1991). The drift velocities are used for the field lines with apex altitude up to $450 \mathrm{~km}$. For field lines with apex altitude $>3000 \mathrm{~km}$, the drift velocity is taken to be zero, and linear interpolation is used at intermediate apex altitudes as in the earlier simulations (Balan and Bailey, 1995). For the neutral dynamics, the neutral wind velocities are obtained from HWM93 model (Hedin et al., 1994). The equivalent wind in the magnetic meridian is given by

$W_{\text {eff }}=(V \cos D \pm U \sin D) \cos (I) \sin (I)$

where $U$ and $V$ are the zonal (positive eastward) and meridional (positive equatorward) winds, $I$ and $D$ are the magnetic inclination and declination, respectively and the + and - signs are for the Southern and Northern Hemispheres (Titheridge, 1995; Jee et al., 2009; Liu et al., 2010). However, the wind velocities given by HWM93 could not fully reproduce the MSNA features. Hence the model simulations are repeated using the MU radar measured meridional wind velocities at solar minimum summer conditions (Kawamura et al., 2000). The model simulations qualitatively reproduce the general MSNA features when the MU radar derived winds are used.

Figure $6 \mathrm{a}-\mathrm{c}$ shows the model inputs. Figure 6a shows the two drift patterns used for the simulations. In the first set of simulations, the vertical $\boldsymbol{E} \times \boldsymbol{B}$ drift velocities corresponding to the solar minimum, geomagnetically quiet summer period (Fejer et al., 1991) is used, which we refer to as "normal" drift; For estimating the effect of an enhanced drift, the values in the evening hours (16:00-20:00 LT) are modified, and this drift pattern is referred to as "modified drift". Figure $6 \mathrm{~b}$ shows the meridional wind variations used for the simulations. The MU radar derived winds differ from the HWM-93 winds from 18:00 LT throughout the night and in the morning hours; at night the MU radar winds are more equatorward than the HWM winds. This difference is large from 20:00 LT to 23:00 LT, with the difference as high as $100 \mathrm{~m} \mathrm{~s}^{-1}$ around 


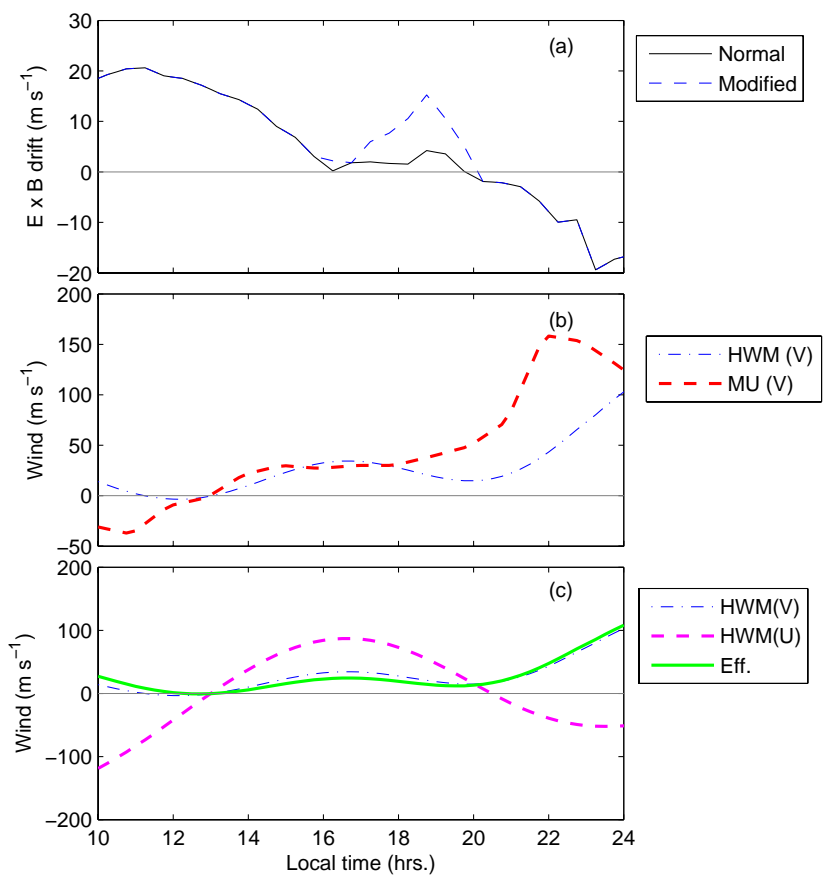

Fig. 6. Model inputs. (a) Local time variation of the two drift patterns used for the simulations. (b) Local time variation of MU radar derived winds and HWM-93 meriodional winds outputs used for simulations. (c) The local time variation of zonal $(U)$, meridional $(V)$ and effective winds obtained from the HWM-93 model, corresponding to $38^{\circ} \mathrm{N}$ magnetic latitude.

22:00 LT. The model simulations with HWM winds correspond to $38^{\circ} \mathrm{N}$ magnetic latitude, where we can see the maximum MSNA development (Liu et al., 2010). Figure 6c shows the zonal $(U)$, meridional $(V)$ and effective winds obtained from the HWM-93 model, corresponding to $38^{\circ} \mathrm{N}$ magnetic latitude. Since the magnetic declination is small, $\left(\sim 6^{\circ} \mathrm{W}\right)$, the contribution of $U$ is insignificant for the effective wind at this latitude (see Eq. 1). Hence the variation of effective wind essentially follows that in $V$. It was reported that the effective neutral wind in this magnetic meridian is essentially equal to meridional neutral wind (Su et al., 1997), since the magnetic declination is very small. Hence, the incorporation of the MU radar-derived meridional wind alone is a reasonable choice to understand the formation of the northern hemispheric MSNA at these longitudes, since the effective wind variation would be identical to that of the MU wind variation.

Figure $7 \mathrm{a}-\mathrm{c}$ shows the LT variation of $N_{\max }$ values obtained from different simulations. These outputs also correspond to $38^{\circ} \mathrm{N}$ magnetic latitude. Figure 7 a shows the outputs with normal drift without any wind input and with the MU radar wind input. When there is no wind, the electron density shows a broad maximum from around 10:0015:00 LT, and then decreases. This decrease becomes faster after $\sim$ 19:00 LT when the solar photoionization stops. This is simple solar controlled behavior, but unrealistic because

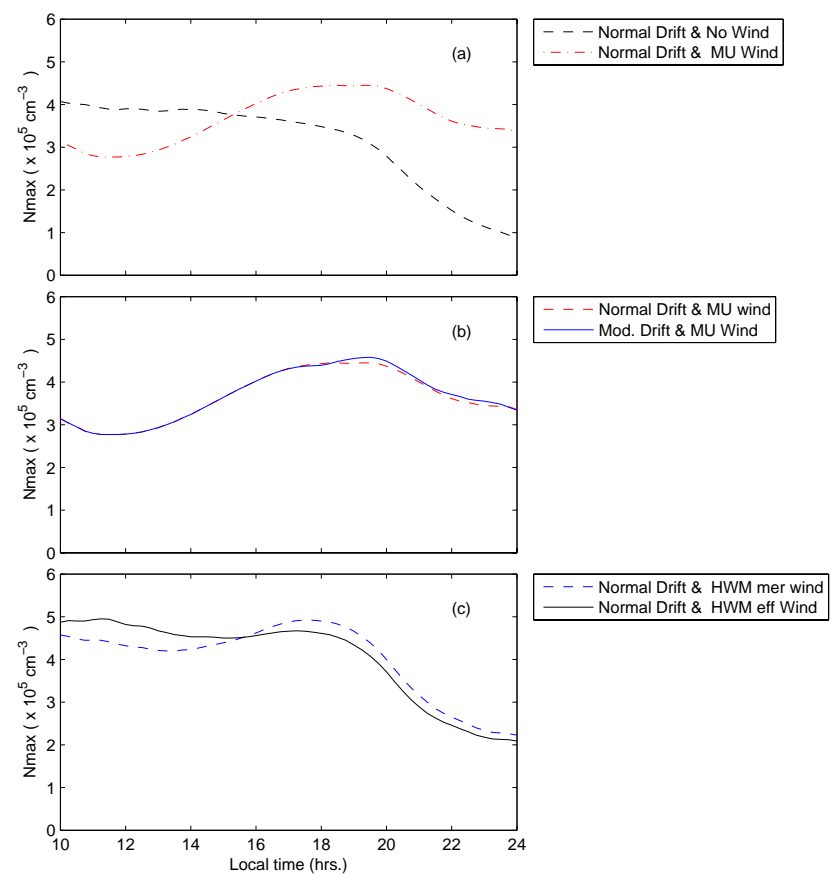

Fig. 7. Local time variation of $N_{\max }$ values obtained from different simulations. These outputs also correspond to $38^{\circ} \mathrm{N}$ magnetic latitude.

in the actual case the winds play a major role in determining the diurnal pattern. The diurnal pattern of $N_{\max }$ changes drastically, when the MU winds are included. The electron density shows the "noon time dip" around 12:00-14:00 LT. After 14:00 LT, the $N_{\max }$ starts to increase and maintains the highest densities up to $\sim 21: 00 \mathrm{LT}$ and the decrease afterwards is also quite slower compared to the "no wind" case. In the mid-latitude F-region the meridional prevailing winds are mainly poleward during daytime and equatorward during nighttime. Su et al. (1997) showed modeling studies of the effects arising from the wind and drift on the diurnal variation of the electron density profiles using MU radar observations and concluded that the thermospheric wind is responsible for making the electron density lower at noon than that at sunset. It must be remembered that the $h m \mathrm{~F} 2$ values over mid-latitudes shows a minimum around noon, and the MU radar winds shows a poleward maximum between 11:00 and 12:00 LT. The wind turns equatorward from around 14:00 LT (Fig. 6b) and this is the time when $N_{\max }$ starts to increase. The density remains high in the night because of the windinduced lifting of the ionosphere where the recombination is slow, and hence the plasma would be preserved for a longer time. Hence, we can conclude that the observed MSNA feature can be reproduced by using a combination of normal drifts and MU winds.

Figure $7 \mathrm{~b}$ shows the LT variation $N_{\max }$ values at $38^{\circ} \mathrm{N}$ magnetic latitude when "normal drift" and "modified drift" are given as inputs along with MU winds. It is seen that the 


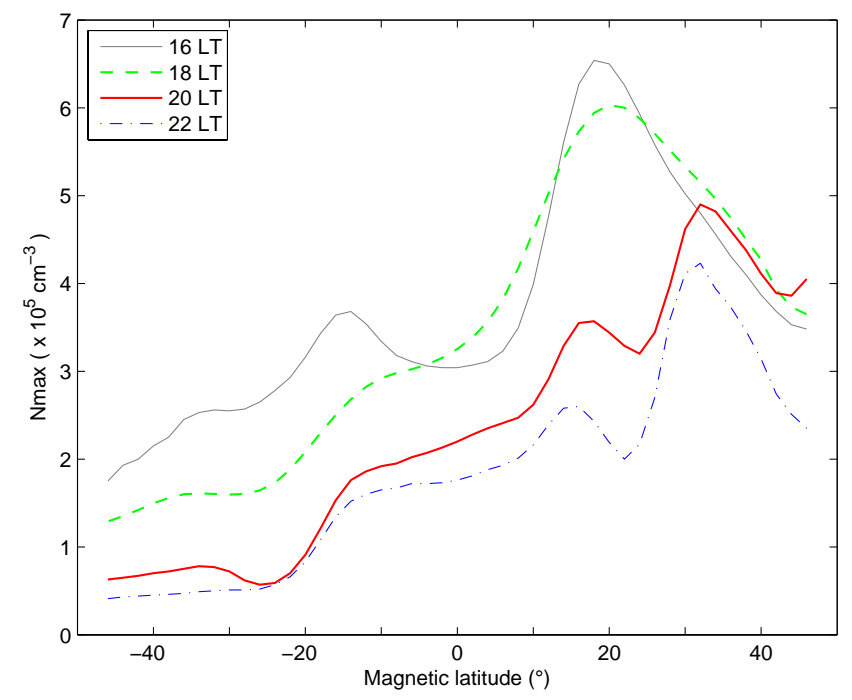

Fig. 8. Latitudinal variation of $N_{\max }$ at 16:00, 18:00, 20:00 and 22:00 LT, obtained using normal drift and MU winds.

density variation remains almost the same in both the cases, indicating that the electron density at $38^{\circ} \mathrm{N}$ magnetic latitude is hardly affected by the changes in the upward drift at the equator. This means that the enhanced densities over this latitude region have no significant contribution from the Equatorial Ionization Anomaly (EIA) crest. During solar minimum the EIA related densities can extend only less than $20^{\circ}$ of magnetic equator, and hence this result is very reasonable.

Figure $7 \mathrm{c}$ shows the LT variation $N_{\max }$ values at $38^{\circ} \mathrm{N}$ magnetic latitude, with normal drift and HWM meridional wind and effective wind. During noontime, the inclusion of the zonal wind reduces the "dip", but the two patterns are nearly identical in the evening hours. The evening time densities are slightly higher than the noontime values, unlike in the "no-wind" case, indicating the role of winds in producing the noon-time dip and maintaining higher densities during the evening hours. However, in both cases, the electron densities start decreasing shortly after 19:00 LT, when the solar photoionization stops, even though the decrease is slower than the "no wind" case. But, the MSNA feature is not wellreproduced with these wind inputs, indicating that the actual wind magnitudes required to generate the MSNA are much higher than that given by the HWM-93.

Figure 8 shows the latitudinal variation of $N_{\max }$ at 16:00, 18:00, 20:00 and 22:00 LT, obtained using MU winds and normal drift. At 16:00 LT, the EIA crests can be seen around $17^{\circ}$ magnetic latitude. It is also seen that the crest in the summer hemisphere is stronger than that in the winter hemisphere. This corroborates with the previous observations that during afternoon hours, the summer EIA crest intensifies and the winter crest start to diminish (Lin et al, 2007). This interhemispheric asymmetry of EIA has been studied previously using model simulations (Balan and Bailey, 1995).

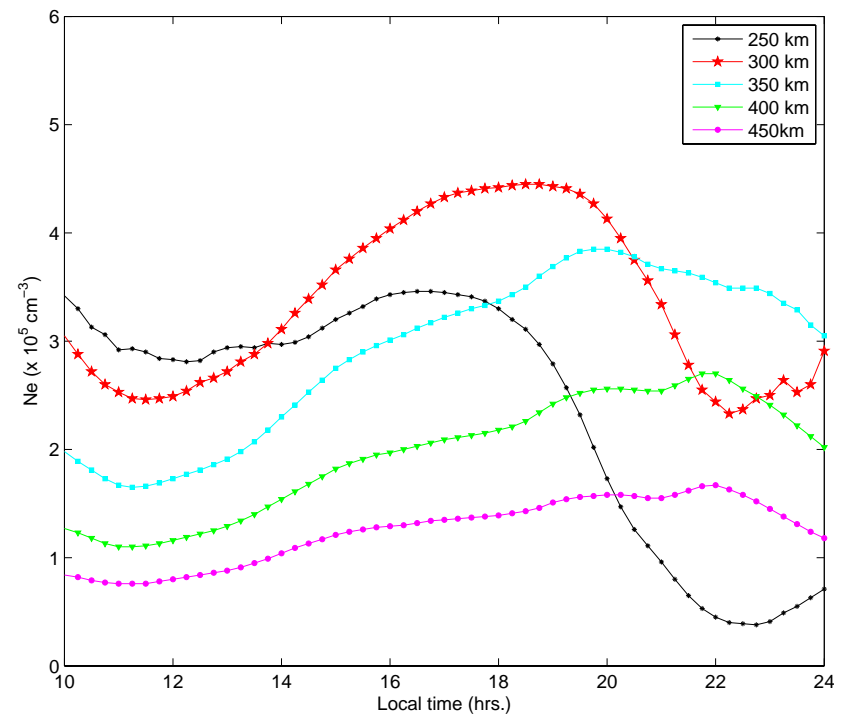

Fig. 9. Local time variation of electron density, at different altitudes corresponding to $38^{\circ} \mathrm{N}$ magnetic latitude. The simulations are done using normal drift and MU winds.

The crests move closer to the equator and further diminish in intensity as the time progresses. The electron density at 16:00 LT is higher than the later hours, and the decrease in density is gradual with time, in the entire winter hemisphere, and upto $\sim 23^{\circ} \mathrm{N}$ magnetic latitude. Beyond this, in the Northern Hemisphere, the evening time densities exceed that at 16:00 LT, and beyond $28^{\circ} \mathrm{N}$ magnetic latitude, the densities at 18:00 LT and 20:00 LT are higher than that at 16:00 LT. This corresponds to the MSNA feature. An interesting factor which is to be noted here is that, in the Southern (winter) Hemisphere, the decrease in electron density from 16:00 LT to 18:00 LT and from 18:00 LT to 20:00 LT are quite significant, and there is no nighttime enhancement. The latitudinal variation of electron density using in situ observations using the Langmuir probe on board CHAMP satellite also showed similar features (Thampi et al., 2009; Liu et al., 2010). If the MSNA feature were due to the cross-L compression of the plasmasphere, and the resultant downward acceleration of thermal plasma along the contracting flux tubes, the enhancements would have appeared at both hemispheres simultaneously. The fact that the changes in the $\boldsymbol{E} \times \boldsymbol{B}$ drift does not produce any significant increase/decrease of MSNA, and the absence of MSNA feature in the Southern (winter) Hemisphere enables us to conclude that the cross- $\mathrm{L}$ compression of the plasmasphere may not be a major factor in the generating MSNA.

Figure 9 shows the LT variation of electron density, at different altitudes, corresponding to $38^{\circ} \mathrm{N}$ magnetic latitude. It is seen that MSNA is absent at $250 \mathrm{~km}$, the density being highest 16:00 LT-18:00 LT, and decreases afterwards. At $300 \mathrm{~km}$ and above the MSNA feature is seen, with a broad density maximum from 16:30 LT-20:00 LT, and a 
clear "noontime dip". This is more or less similar to the $N_{\max }$ variation, because model resolution is $50 \mathrm{~km}$, and in the afternoon and evening hours the peak occurs at $300 \mathrm{~km}$. MSNA is a feature that exists more clearly at 350 and $400 \mathrm{~km}$, and to a lesser extent (in terms of noon-night difference) at $450 \mathrm{~km}$. This agrees fairly well with the F3/C observations (Fig. 2) and previous observations of Weddell Sea anomaly (WSA) and MSNA (Lin et al., 2009). However, the simulated densities show a minimum around 23:00 LT and then tend to show a small increase. This is not observed, and seems to be due to not including the altitude variation of the wind velocities in the model calculations; MU radar observations give only altitude averaged wind patterns (Kawamura et al., 2000). At this point, we think this feature is unrealistic. The change in the peak height from 250 to $300 \mathrm{~km}$ at 14:00 LT in the simulation output is reasonable because the meridional winds turn equatorward around 13:00 LT, and we can expect a height rise of the ionosphere due to these winds. The monthly mean values from Wakkanai shows a height rise from 14:00 LT, with a gradual increase in the base-height of the F-layer from $210 \mathrm{~km}$ at 14:00 LT to $240 \mathrm{~km}$ at 18:00 LT. Apart from these two differences, MSNA is captured well in the appropriate altitudes, and qualitatively agree well with the observations.

\section{Discussion}

The most important mechanism suggested for the formation of MSNA is the neutral wind effect in the geomagnetic frame. Comparing the electron density at the MSNA region at 16:00-18:00 LT with that at 20:00 LT (Fig. 4), it can be seen that there is an additional accumulation of ionization at the same altitude at latitudes $>\sim 35^{\circ} \mathrm{N}$, which begins after 16:00 LT (when solar photoionization is still present). It is noted that sunset at the F-region occurs around 18:5019:00 LT at $40^{\circ} \mathrm{N}$. Hence, densities at this region in the image corresponding to 20:00 LT correspond to the time close to and after the F-region sunset, which can be understood as a consequence of the wind-induced lifting of the ionosphere. The magnitude of the winds and the magnetic inclination and declination angles are the factors affecting the amount of plasma in the nighttime mid-latitude F-region (Rastogi, 1960; Jee et al., 2009).

The evening enhancement in the $N m \mathrm{~F} 2$ during summer months was explained by Rishbeth $(1966,1967)$ on the basis of the later occurrence of local sunset and equatorward winds. It was explained that if the equatorward wind - induced uplift of the plasma occur before solar photoionization ceases, the plasma is lifted to a region where the recombination is slow, and as a result, the $N m \mathrm{~F} 2$ would show an increase and the plasma would be preserved for a longer time. Since the magnetic declination angle is small (at MU radar location, the declination is only $6^{\circ} \mathrm{W}$ ), the geographic meridional winds would be effective in blowing the ionization vertically up. Using semi-empirical calculations, it was shown that at MU radar location, $h m \mathrm{~F} 2$ moves roughly $1 \mathrm{~km}$ per $1 \mathrm{~ms}^{-1}$ of meridional wind applied (Oliver et al., 2008).

Recently, He et al. (2009) have discussed the relative importance of various processes in the generation of WSA. It is reported that the increase in the F-layer height and density can occur in periods with either enhancing equatorward winds or weakening poleward winds before the local sunset, an increase in $N m \mathrm{~F} 2$ could be induced. Hence, the increase could be set in as early as 14:00 LT, though the equatorward wind may appear much later. In the diurnal pattern of $N_{\mathrm{e}}(300 \mathrm{~km})$ and $N m \mathrm{~F} 2$ (Figs. 4 and 5), we can see that after the diurnal minimum at $\sim 12: 00 \mathrm{LT}$, the densities began to increase in the afternoon hours, which corroborates with this explanation. It can be seen that, diurnally the minimum value of $h m \mathrm{~F} 2$ occurs at 11:00-12:00 LT, and the enhancement in the $h m \mathrm{~F} 2$ sets in at $\sim 14: 00-16: 00 \mathrm{LT}$ (Fig. 5). The maximum of $h m \mathrm{~F} 2$ is observed around 22:00-24:00 LT, when the maximum equatorward winds are observed (Kawamura et al., 2000). Hence, the $h m \mathrm{~F} 2$ variation also suggests that that the increase in the F-layer height can set in with the weakening of the poleward winds. When we give the MU radar winds as input to the SUPIM simulations, the MSNA is reproduced, whereas the mid-latitude electron density pattern is seen to be hardly affected by the changes in the eastward drift at the equator confirming the argument that neutral wind is the main driver for MSNA. One of the major results of the simulation is that the zonal electric field at the equator has little contribution to the formation of the MSNA (Fig. 7b). The enhanced vertical drift in the evening have little effect on the electron density at $38^{\circ} \mathrm{N}$ magnetic latitude where the MSNA maximizes. Thus this simulation disconfirms the speculation by Lin et al. (2010), where the electric field was suggested to be a main factor for MSNA formation.

Using MU radar observations and semi empirical modeling, Oliver et al. (2008) have found that the diurnal variation of $h m \mathrm{~F} 2$ is driven most importantly by winds, and secondly by thermal expansion/contraction of the thermosphere. They also found that the $N_{\max }$ is proportional to the ratio of the atomic and molecular densities at the altitude of $h m \mathrm{~F} 2$ but this ratio is insensitive to thermal expansion. A decrease in the $[\mathrm{O}] /\left[\mathrm{N}_{2}\right]$ ratio could decreases the electron density due to increased recombination. Hence, we can understand that the effect of thermal expansion comes into play by its influence on determining the $h_{\max }$ altitude along with winds, aiding the formation of MSNA at a particular longitude.

The other important factor which is invoked to explain the seasonal pattern of MSNA is the fast downward plasma diffusion induced by the thermal contraction of the ionosphere which can lead to more efficient accumulation of plasma near and above $h m \mathrm{~F} 2$ in summer than in winter (Liu et al., 2010). To check whether the thermal contraction of the ionosphere has any significant longitudinal difference, we compared the rate of change of electron temperature $\left(T_{\mathrm{e}}\right)$ with time at these two longitudes using CHAMP measurements (Fig. 10). It was found that though the absolute magnitudes of $T_{\mathrm{e}}$ are 


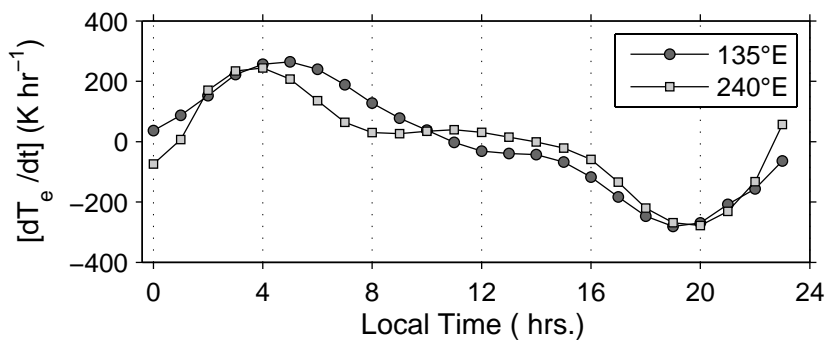

Fig. 10. LT variation of rate of change of $T_{\mathrm{e}}$ corresponding to $135^{\circ} \mathrm{E}$ and $240^{\circ} \mathrm{E}$, for $40^{\circ} \mathrm{N}$ latitude, from CHAMP data.

slightly different at these two longitudes (not shown), their rate of change with time is almost identical (Fig. 10), indicating equal thermal contraction rates at these two sectors. Hence, this factor does not become crucial to explain the longitude structure of MSNA, though it may be important to explain why MSNA does not occur in winter. Thus, the observations as well as the model simulations clearly show that the neutral wind in the geomagnetic frame can produce both the daytime depletion, and the night time enhancement, and hence generation of MSNA, revealing yet another striking aspect of the coupled ion-neutral dynamics.

\section{Summary}

The simulations reveal the following important aspects about the formation of MSNA:

(1) In the Northern Hemisphere, the change in the eveningtime $\boldsymbol{E} \times \boldsymbol{B}$ drift does not have any significant effect in the density pattern at mid-latitudes, suggesting that the earlier consideration by Lin et al. (2010) is not very effective. (2) The noon time dip and the evening enhancements are closely related to the diurnal variation in the thermospheric meridional winds. The MSNA is not well simulated by using the averaged model wind. Instead, by using the MU radar observed wind (i.e., local realistic wind), we could simulate the MSNA much better. This corroborates with the behavior that the MSNA shows significant longitudinal variation, and is enhanced around the Japanese longitudes. The observations as well as simulations confirm the importance of equatorward neutral winds in the formation of MSNA, and the mechanism is similar to the equatorward wind producing positive ionospheric storms (Balan et al., 2009). (3) The HWM-93 wind magnitudes do not realistically represent the meridional wind magnitudes over Japanese longitudes, and hence are insufficient to generate the MSNA feature in the simulations. Assimilation of MU radar winds to the SUPIM model enables us to qualitatively reproduce all the features of the MSNA.

Acknowledgements. The work of ST and HL is supported by the Japan Society for the Promotion of Science (JSPS) foundation. We thank NICT, Japan, for the ionosonde data, UCAR CDAAC (http://www.cosmic.ucar.edu), TACC of Taiwan CWB for the F3/C data and NSPO operational team for the F3/C tri-band beacon experiment.

Topical Editor K. Kauristie thanks I. Horvath and P. Sree Brahmanandam for their help in evaluating this paper.

\section{References}

Anthes, R. A., Bernhardt, P. A., Chen, Y., Cucurull, L., Dymond, K. F., Ector, D., Healy, S. B., Ho, S.-P., Hunt, D. C., Kuo, Y.-H., Liu, H., Manning, K., Mccormick, C., Meehan, T. K., Randel, W. J., Rocken, C., Schreiner, W. S., Sokolovskiy, S. V., Syndergaard, S., Thompson, D. C., Trenberth, K. E., Wee, T.-K., Yen, N. L., and Zeng, Z.: The COSMIC/FORMOSAT-3 mission: Early Results, B. Am. Meteorol. Soc., 89, 3-13, doi:10.1175/BAMS89-3-313, 2008.

Bailey, G. J., Sellek, R., and Balan, N.: The effect of interhemispheric coupling on nighttime enhancements in ionospheric total electron content during winter at solar minimum, Ann. Geophys., 9, 734-747, 1991.

Bailey, G. J., Balan, N., and Su, Y. Z.: The Sheffield University plasmasphere ionosphere model: A review, J. Atmos. Sol. Terr. Phys., 59, 1541-1552, 1997.

Balan, N. and Bailey, G.: Latitudinal Variations of Nighttime Enhancements in TEC: solar and magnetic activity effects, Adv. Space Res., 12(6), 219-222, 1992.

Balan, N. and Bailey, G.: Equatorial Plasma Fountain and its Effects: Possibility of an Additional Layer, J. Geophys. Res., 100(A11), 21421-21432, 1995.

Balan, N. and Rao, P. B.: Latitudinal Variations of Nighttime Enhancements in Total Electron Content, J. Geophys. Res., 92(A4), 3436-3440, 1987.

Balan, N., Bailey, G. J., Balachandran Nair, R., and Titheridge, J. E.: Nighttime enhancements in ionospheric electron content in the northern and southern hemispheres, J. Atmos. Terr. Phys., 56(1), 67-79, 1994.

Balan, N., Shiokawa, K., Otsuka, Y., Watanabe, S., and Bailey, G. J.: Super plasma fountain and equatorial ionization anomaly during penetration electric field, J. Geophys. Res., 114, A03310, doi:10.1029/2008JA013768, 2009.

Bellchambers, W. H. and Piggott, W. R.: Ionospheric measurements made at Halley Bay, Nature, 182, 1596-1597, doi:10.1038/1821596a0, 1958.

Davies, K., Anderson, A. K., Paul, W., Degenhart, G. K., Hartmann, G. K., Leitinger, R.: Night-time increases in total electron content observed with ATS 6 radio beacon, J. Geophys. Res., 84, 1536-1542, 1979.

Evans, J. V.: Cause of the Mid-Latitude evening Increase in $f o F 2$, J. Geophys. Res., 70, 1175-1185, 1965.

Fejer, B. G., De Paula, E. R., Gonzalez, S. A., and Woodman, R. F.: Average vertical and zonal $F$ region plasma drifts over Jicamarca, J. Geophys. Res., 96, 13901-13906, 1991.

Hajj, G. A., Lee, L. C., Pi, X., Romans, L. J., Schreiner, W. S., Straus, P. R., and Wang, C. M.: COSMIC GPS ionospheric sensing and space weather, Terr. Atmos. Oceanic Sci., 11(1), 235273, 2000.

He, M., Liu, L., Wan, W., Ning, B., Zhao, B., Wen, J., Yue, X., and Le, H.: A study of the Weddell Sea Anomaly observed 
by FORMOSAT-3/COSMIC, J. Geophys. Res., 114, A12309, doi:10.1029/2009JA014175, 2009.

Hedin, A. E., Buonsanto, M. J., Codrescu, M., Duboin, M. L., Fesen, C. G., Hagan, M. E., Miller, K. L., and Sipler, D. P.: Solar activity variations in the midlatitude thermospheric meridional winds, J. Geophys. Res., 99, 17601-17608, 1994.

Horvath, I.: A total electron content space weather study of the nighttime Weddell Sea Anomaly of 1996/1997 southern summer with TOPEX/Poseidon radar altimetry, J. Geophys. Res., 111, A12317, doi:10.1029/2006JA011679, 2006.

Horvath, I. and Essex, E. A.: Using observations from the GPS and TOPEX satellites to investigate night-time TEC enhancements at midlatitudes in the southern hemisphere during a low sunspot number period, J. Atmos. Solar Terr. Phys., 62, 371-391, doi:10.1016/S1364-6826(99) 00101-7, 2000.

Horvath, I. and Essex, E. A.: The Weddell sea anomaly observed with the TOPEX satellite data, J. Atmos. Sol. Terr. Phys., 65, 693-706, 2003.

Horvath, I. and Lovell, B. C.: An investigation of the northern hemisphere midlatitude nighttime plasma density enhancements and their relations to the midlatitude nighttime trough during summer, J. Geophys. Res., 114, A08308, doi:10.1029/2009JA014094, 2009.

Jee, G., Burns, A. G., Kim, Y.-H., and Wang, W.: Seasonal and solar activity variations of the Weddell Sea Anomaly observed in the TOPEX total electron content measurements, J. Geophys. Res., 114, A04307, doi:10.1029/2008JA01380, 2009.

Kawamura, S., Otsuka, Y., Zhang, S.-R., Fukao, S., and Oliver, W. L.: A climatology of middle and upper atmosphere radar observations of thermospheric winds, J. Geophys. Res., 105(A6), 12777-12788, 2000.

Lin, C. H., Liu, J. Y., Fang, T. W., Chang, P. Y., Tsai, H. F., Chen, C. H., and Hsiao, C. C.: Motions of the equatorial ionization anomaly crests imaged by FORMOSAT3/COSMIC, Geophys. Res. Lett., 34, L19101, doi:10.1029/2007GL030741, 2007.

Lin, C. H., Liu, J. Y., Cheng, C. Z., Chen, C. H., Liu, C. H., Wang, W., Burns, A. G., and Lei, J.: Three-dimensional ionospheric electron density structure of the Weddell Sea Anomaly, J. Geophys. Res., 114, A02312, doi:10.1029/2008JA013455, 2009.

Lin, C. H., Liu, C. H., Liu, J. Y., Chen, C. H., Burns, A. G., and Wang, W.: Midlatitude summer nighttime anomaly of the ionospheric electron density observed by FORMOSAT3/COSMIC, J. Geophys. Res., 115, A03308, doi:10.1029/2009JA014084, 2010.

Liu, H., Thampi, S. V., and Yamamoto, M.: Anomalous Phase Reversal of the Diurnal Cycle in the Mid-latitude Ionosphere, J. Geophys. Res., 115, A01305, doi:10.1029/2009JA14689, 2010.
Liu, J. Y., Lin, C. Y., Lin, C. H., Tsai, H. F., Solomon, S. C., Sun, Y. Y., Lee, I. T., Schreiner, W. S., and Kuo, Y. H.: Artificial plasma cave in the low-latitude ionosphere results from the radio occultation inversion of the FORMOSAT 3/COSMIC, J. Geophys. Res., 115, A07319, doi:10.1029/2009JA015079, 2010.

Luan, X., Wang, W., Burns, A., Solomon, S. C., and Lei, $\mathrm{J}$.: Midlatitude nighttime enhancement in $\mathrm{F}$ region electron density from global COSMIC measurements under solar minimum winter condition, J. Geophys. Res., 113, A09319, doi:10.1029/2008JA013063, 2008.

Oliver, W. L., Kawamura, S., and Fukao, S.: The causes of mid-latitude F layer behavior, J. Geophys. Res., 113, A08310, doi:10.1029/2007JA012590, 2008.

Rastogi, R. G.: Abnormal features of the region of the ionosphere at some southern high-latitude stations, J. Geophys. Res., 65, 585592, 1960.

Rishbeth, H.: The effect of winds on the ionnospheric F2-peak, J. Atmos. Terr. Phys., 29, 225-238, 1966.

Rishbeth, H.: The effect of winds on the ionnospheric F2-peak, J. Atmos. Terr. Phys., 30, 63-71, 1967.

Su, Y. Z., Fukao, S., and Bailey, G. J.: Modeling studies of the middle and upper atmosphere radar observations of the ionospheric F layer, J. Geophys. Res., 102(A1), 319-327, 1997.

Syndergaard, S., Schreiner, W. S., Rocken, C., Hunt, D. C., and Dymond, K. F.: Preparing for COSMIC: Inversion and analysis of ionospheric data products, in Atmosphere and Climate: Studies by Occultation Methods, edited by: Foelsche, U., Kirchengast, G., and Steiner, A. K., pp. 137-146, Springer-Verlag, Berlin Heidelberg, 2006.

Thampi, S. V., Lin, C. H., Liu, H., and Yamamoto, M.: First Tomographic Observations of the Mid-latitude Summer Nighttime Anomaly (MSNA) over Japan, J. Geophys. Res., 114, A10318, doi:10.1029/2009JA014439, 2009.

Thampi, S. V. and Yamamoto, M.: First results from the ionospheric tomography experiment using beacon TEC data obtained using a network along $136^{\circ}$ E longitude over Japan, Earth Planets Space, 62, 359-364, 2010.

Titheridge, J. E.: Nighttime Changes in the Electron Content of the Ionosphere, J. Geophys. Res., 73(9), 2985-2993, 1968.

Titheridge, J. E.: Winds in the ionosphere -A review, J. Atmos. Terr. Phys., 57(14), 1681-1714, 1995. 